\title{
Motor recovery of patients presenting with motor paralysis and sensory sparing following cervical spinal cord injuries
}

\author{
S Katoh and WS El Masry \\ The Midlands Centre for Spinal Injuries, The Robert Jones and Agnes Hunt Orthopaedic and District Hospital, \\ Oswestry, Shropshire SY10 7AG, UK
}

\begin{abstract}
We studied the neurological progress of 21 consecutive patients with cervical spinal cord injuries, presenting with sensory sparing but with complete motor paralysis below the level of their injury (Frankel B). All patients were admitted within $48 \mathrm{~h}$ of injury and treated conservatively with 6 weeks of bedrest and traction, followed by 6 weeks of bracing. The follow-up period was more than 1 year (49.6 months on average). Despite the initial absence of motor power in the lower limbs, seven patients recovered significant motor power and were able to walk. The preservation of pinprick sensation between the level of the injury and the sacral dermatomes was the best prognostic indicator for useful motor recovery with $75 \%$ of the patients regaining the ability to walk. This pattern of sensory sparing predicted a statistically significant better motor outcome than other patterns of sensory sparing. Although $50 \%$ of patients with no sacral sensation and/or with anal sensation on rectal examination recovered motor power, this recovery was functional in only one out of eight patients.
\end{abstract}

Keywords: spinal cord injury; cervical vertebrae; paralysis; neurological recovery

\section{Introduction}

The poor prognosis of patients who sustained complete somatosensory loss (Frankel A) following spinal injuries, is well documented. ${ }^{1,2}$ The preservation of sensation without motor power (Frankel B) is also considered to be followed by poor functional outcome. ${ }^{3}$ Significant motor recovery can however occur in this group of patients. ${ }^{1,4-6}$ The modality of the sensation spared was found to be a good prognostic indicator of motor recovery. ${ }^{7}$ Many patients with spinothalamic sensory sparing had a good chance of recovering significant motor power to ambulate. ${ }^{8}$ Other reports confirmed this observation..$^{5,9}$ The purpose of this study is to define the prognostic value of the pattern and the extent of spinothalamic sensory sparing in Frankel B tetraplegic patients.

\section{Patients and methods}

Twenty one adult consecutive patients admitted between January 1983 and December 1991 with incomplete sensory sparing but with no motor sparing were included in this study. All patients were classified as Frankel grade B. The patients were admitted within 2 days of injury and were treated conservatively. We excluded patients with double injuries of the spinal axis, roots or plexus injuries, or skeletal injuries interfering with accurate neurological documentation. We also excluded patients treated surgically. Sensory sparing was defined when there was preservation of sensation (either continuously or in patches) in any of the dermatomes distal to the four dermatomes below the last normal segment. ${ }^{10}$ Eight patients were admitted on the day of injury, 10 patients the next day and three patients within $48 \mathrm{~h}$ from injury. There were 18 male and three female patients. The age at the time of the injuries ranged between 16 and 69 years (33.2 years on average) and the follow-up period ranged between 12 and 120 months (49.6 months on average). The causes of their injuries are listed in Table 1.

Conservative treatment consisted of bedrest with skull traction for 6 weeks followed by mobilization in a brace for further 6 weeks. Patients with hyperextension injury without bony injury were usually treated with 4 weeks of bedrest. Anti-coagulant therapy and $\mathrm{H}_{2}$ receptor antagonist were administered to almost all patients. Closed reduction with slow incremental weights with or without manipulation was attempted in

Table 1 Causes of injuries to the spinal cord in the 21 patients

\begin{tabular}{lcc}
\hline Cause & Number & Percentage \\
\hline Road traffic accidents & 13 & 61.9 \\
Falls from heights & 4 & 19.0 \\
Diving & 2 & 9.5 \\
Falls on level ground & 1 & 4.8 \\
Rugby & 1 & 4.8 \\
Total & 21 & \\
\hline
\end{tabular}


four patients within $48 \mathrm{~h}$ following injury and two of these patients required general anaesthesia. Methylprednisolone was not administered to any of these patients. The stability of the spine was assessed radiographically by dynamic views at 6 weeks and 12 weeks following injury. There were no major complications except that one patient developed deep vein thrombosis. Total time from injury to the discharge into community was 187.4 days on average.

The neurological status was recorded according to the original Frankel classification and American Spinal Injury Association (ASIA) motor score. ${ }^{1,10}$

For the sensory documentation, the patients were divided into three groups. Group 1 consisted of eight patients with sacral pinprick sensation (sharp or dull) as well as sharp appreciation of pinprick sensation between the level of injury and the sacral dermatomes. Group 2 consisted of five patients with appreciation of pinprick sensation as a dull sensation in the sacral dermatomes as well as between the level of injury and the sacral dermatomes. Group 3 consisted of eight patients without sensation in the sacral dermatomes but with possible preservation of deep anal sensation on rectal examination, together with varied appreciation of pinprick sensation between the level of injury and the sacral dermatomes.

The motor score (MS) was calculated from the summation of the MRC grade of five key muscles in each extremity totalling 100 for a full score. The cervical column injuries in these patients were between C3 and C7 and their types are listed in Table 2 according to the Allen's classification. ${ }^{11}$

\section{Results}

Spontaneous neurological deterioration was recorded in three patients. One patient with blunting of pinprick sensation in the sacral area only and another patient with no sacral sparing who suffered from ankylosing spondylitis lost sensation below the level of the injury 1 day after their accident. Both recovered to the initial neurological status without surgical treatment. Their motor scores (MS) were improved by four points in the former patient (from 22 to 26 ) and by 12 points (from 6 to 18) in the latter. These recoveries were in the myotomal distribution at the site of the injury; however no recovery in the lower limbs occurred. Another

Table 2 The types of cervical injuries, according to the mechanistic classification by Allen et al, ${ }^{11}$ of the 21 patients reviewed

\begin{tabular}{lcc}
\hline Type of injury & Number & Percentage \\
\hline Compressive flexion & 9 & 42.9 \\
Distractive flexion & 5 & 23.8 \\
Compressive extension & 2 & 9.5 \\
Distractive extension or & 3 & 14.3 \\
Vertical compression & 1 & 4.7 \\
Unclassified (ankylosing spondylitis) & 1 & 4.7 \\
Total & 21 & \\
\hline
\end{tabular}

patient in Frankel B lost motor power from one spinal cord segment at the site of injury 13 days following the accident. This patient recovered motor power in the lower limbs to Frankel $\mathrm{C}$ within 19 months and his MS improved to 64 . The motor power improvement is shown in Figure 1.

Of the 21 patients presenting in Frankel B on admission, 16 patients recovered motor power in the lower limbs and five patients remained in Frankel B. Of those who recovered motor power in the lower limbs, eight improved to Frankel C, six to Frankel D and two to Frankel E. In total, $29 \%$ of the patients recovered significantly enough to walk (Table 3 ). In trying to correlate the pattern of sensory sparing with the ability to walk at the latest follow-up more that 1 year from the accidents, it was found that $75 \%$ of group 1 patients were able to walk, $20 \%$ of group 2 patients achieved walking and only $12.5 \%$ of group 3 patients were able

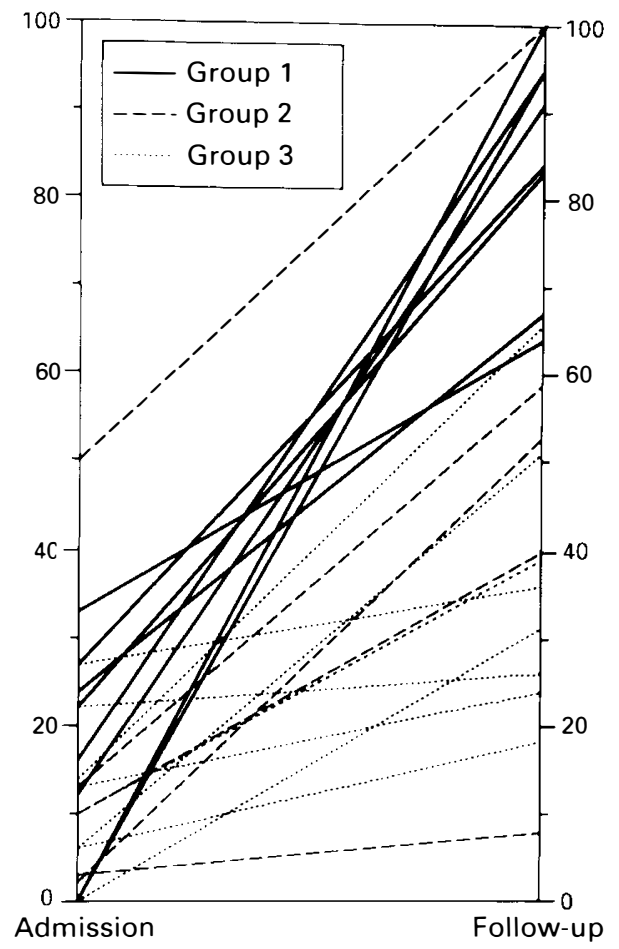

Figure 1 The progress in motor score of the 21 patients presenting in Frankel B on admission. Full lines represent group 1, broken lines group 2 and dotted lines group 3

Table 3 Type of ambulation in the various groups

\begin{tabular}{lccc}
\hline Ambulation & Group 1 & Group 2 & Group 3 \\
\hline Community & 4 & 1 & 0 \\
Household & 1 & 0 & 0 \\
Non-functional & 2 & 2 & 5 \\
Non-ambulator & 1 & 2 & 3 \\
Total & 8 & 5 & 8 \\
\hline
\end{tabular}

Group $1 v s$ groups 2 and 3, $P<0.05$, Mann-Whitney $U$ test 
to walk (Table 4). Comparing the first group with the last two groups combined together, there was a statistically significant difference between these incidences $(P=0.02$, Fisher's exact probability test $)$. There was also statistically significant difference between MS recovery in the lower limbs of groups 1 and patients groups 2 and 3 combined together $(40.3 \pm 10.7 \mathrm{vs}$ $16.5 \pm 16.0, P<0.001$, two-tailed unpaired $t$ test). In other words, patients with spinothalamic sensory preservation between the level of the injury and the last sacral dermatomes did much better than those with dull sensation in the sacral dermatomes and patchy dullness or anaesthesia between the level of the injury and the sacral dermatomes. Absence of sacral dermatome sensation despite the presence of partial rectal (PR) sensation was followed by the least recovery.

\section{Discussion}

The preservation of the function of the sacral segments has been regarded as an important factor to predict the degree of functional recovery after spinal cord injury. ${ }^{2}$ Waters et al reported the consistency of sacral neurology in the definition of complete spinal cord injury. ${ }^{12}$ This was also adopted by the American Spinal Injury Association Standards for definition and documentation following spinal injuries. ${ }^{10}$ In this series of patients without sacral sparing, the incidence of motor recovery in the lower limbs (four out of eight) was significantly higher $(P=0.002$, Fisher's exact probability test $)$ than in the series of patients with complete injury where only one out of 40 patients recovered to Frankel C. ${ }^{13}$

The preservation of spinothalamic sensation was found to be a prognostic indicator of good recovery in patients presenting in Frankel B. ${ }^{8}$ This was later confirmed by Crozier et al and Waters et al.$^{5,9}$ The reason that some patients with spinothalamic sensory sparing did not make a significant recovery was not however clear. Our findings suggest that the extent of sparing is at least as important as the modality of sparing (the spinothalamic tract). Spinothalamic tract sensory preservation between the level of the injury and the sacral dermatomes suggests more sparing of the white matter of the cervical spinal cord which is necessary for the return of significant motor function. Dull sensation with patchy area of anaesthesia or dull sensation in the sacral dermatomes only was not associated with significant recovery. Only one out of five patients in group 2 recovered significantly. In this patient, dullness was appreciated without interruption throughout the body down to the level of the fifth sacral dermatome. Dull sensory response to pinprick was followed by insignificant motor recovery in three out of five patients, suggesting that the white matter is pathological. Although some motor recovery may occur, it is unlikely to be of functional use in the majority of the patients.

The lack of all sensory response to pinprick (sharp or dull) in the sacral dermatomes despite the preservation of some anal deep sensation on rectal examination and some preservation of patchy sensation below the level of the lesion seems to indicate marked damage to the white matter and a poor chance of recovery (Figure 2).

This study concludes that not only the modality of

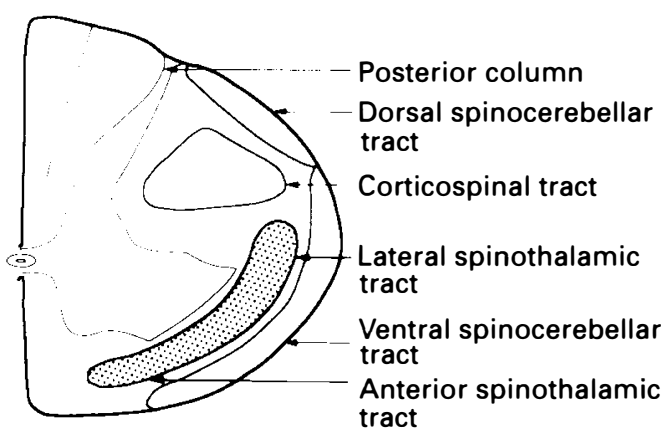

Figure 2 Schematic drawing of spinal tracts in the cervical spinal cord

Table 4 Neurological progress according to the appreciation of pinprick in Frankel B patients on admission

\begin{tabular}{|c|c|c|c|c|c|}
\hline \multicolumn{2}{|r|}{ Response to pinprick } & \multicolumn{4}{|c|}{ Follow-up Frankel grade } \\
\hline $\begin{array}{l}\text { Sacral dermatomes } \\
\text { (S3-5) }\end{array}$ & $\begin{array}{l}\text { Dermatomes between the level of injury and the sacral } \\
\text { dermatomes }^{\text {a }}\end{array}$ & $B$ & $C$ & $D$ & $E$ \\
\hline \multicolumn{6}{|l|}{ Group 1} \\
\hline Sharp & Sharp throughout & 0 & 1 & 2 & 1 \\
\hline Sharp & Sharp with patchy areas of anaesthesia & 0 & 1 & 0 & 0 \\
\hline Dull & Mixed sharp, dull and area of anaesthesia & 0 & 0 & 3 & 0 \\
\hline \multicolumn{6}{|l|}{ Group 2} \\
\hline Dull & Dull throughout & 0 & 1 & 0 & 1 \\
\hline Dull & Dull with patchy areas of anaesthesia & 0 & 1 & 0 & 0 \\
\hline Dull, patchy sharp & Anaesthesia & 1 & 1 & 0 & 0 \\
\hline \multicolumn{6}{|l|}{ Group 3} \\
\hline Nil or felt only $\mathrm{PR}^{\mathrm{b}}$ & Various responses & 4 & 3 & 1 & 0 \\
\hline
\end{tabular}

aThe level of injury considered to include the four segments below the last normal segment

bPatients who felt vague sensation during rectal examination were included 
sensory sparing but also its pattern and extent together are reliable prognostic indicators of useful recovery or lack of it. It is therefore important to qualify the modality of sensory sparing as well as the extent of sparing in order to predict a motor recovery. This is especially important for the comparison of outcome of different management procedures and pharmacological agents.

\section{Acknowledgements}

We are thankful to all the consultants who trust us to treat their patients from an early stage following injury, and for the help we received from Mr S Eisenstein, Mr D Jaffray, Dr I McCall, Professor B O'Connor, Mr R Pringle, Dr V Pullicino, Professor T Ikata and Professor J Templeton.

\section{References}

1 Frankel HL et al. The value of postural reduction in the initial management of closed injuries of the spine with paraplegia and tetraplegia. Part I. Paraplegia 1969; 7: 179-192.

2 Stauffer ES. Diagnosis and prognosis of acute cervical spinal cord injury. Clin Orthop 1975; 112: 9-15.

3 Bosch A, Stauffer ES, Nickel VL. Incomplete traumatic quadriplegia. A ten-year review. JAMA 1971; 216: 473-478.
4 El Masri WS, Jaffray D. Recent developments in the management of injuries of the cervical spine. In: Frankel HL (ed). Handbook of Clinical Neurology. Vol. 17 (61). Spinal Cord Trauma. Elsevier Science Publishers BV: Amsterdam, pp 55-73.

5 Waters RL, Adkins RH, Yakura JS, Sie I. Motor and sensory recovery following incomplete tetraplegia. Arch Phys Med Rehabil 1994; 75: 306-311.

6 Anderson PA, Bohlman HH. Anterior decompression and arthrodesis of the cervical spine: Long-term motor improvement. Part II-Improvement in complete traumatic quadriplegia. J Bone Joint Surg Am 74: 683-692.

7 Foo D, Subrahmanyan TS, Rossier AB. Post-traumatic acute anterior spinal cord syndrome. Paraplegia 1981; 19: 201-205.

8 Folman Y, El Masri W. Spinal cord injury: prognostic indicators. Injury 1989; 20: 92-93.

9 Crozier KS, Graziani V, Ditunno JF Jr, Herbison GJ. Spinal cord injury: prognosis for ambulation based on sensory examination in patients who are initially motor complete. Arch Phys Med Rehabil 1991; 72: 119-121.

10 Ditunno JF Jr, Young W, Donovan WH, Creasey G. The international standards booklet for neurological and functional classification of spinal cord injury. Paraplegia 1994; 32: 70-80.

11 Allen BL Jr, Ferguson RL, Lehmann TR, O'Brien RP. A mechanistic classification of closed, indirect fractures and dislocations of the lower cervical spine. Spine 1982; 7: 1-27.

12 Waters RL, Adkins RH, Yakura JS. Definition of complete spinal cord injury. Paraplegia 1991; 29: 573-581.

13 Katoh S, El Masry WS. Neurological recovery after conservative treatment of cervical cord injuries. J Bone Joint Surg $\mathrm{Br}$ 1994; 76: 225-228. 